\title{
Türkiye'deki Düşünce Kuruluşlarının Sosyal Medya Kullanımları Üzerine Bir İnceleme
}

\author{
Önder Kutlu ${ }^{1}$ (iD) Niyazi Karabulut ${ }^{2}$ \\ Prof. Dr., Necmettin Erbakan Üniversitesi, Siyaset Bilimi ve Kamu Yönetimi, Konya, Türkiye \\ okutlu@erbakan.edu.tr \\ ${ }^{2}$ Arş. Gör., Necmettin Erbakan Üniversitesi, Siyaset Bilimi ve Kamu Yönetimi, Konya, Türkiye \\ nkarabulut@erbakan.edu.tr (Sorumlu Yazar/Corresponding Author)
}

\begin{tabular}{|c|c|}
\hline Makale Bilgileri & ÖZ \\
\hline $\begin{array}{l}\text { Makale Geçmişi } \\
\text { Geliş: 05.04.2021 } \\
\text { Kabul: } 14.05 .2021 \\
\text { Yayın: } 30.06 .2021 \\
\text { Anahtar Kelimeler: } \\
\text { Düşünce kuruluşları, } \\
\text { Etki kapasitesi, Sosyal } \\
\text { medya, Türkiye, Kamu } \\
\text { politikası } \\
\text { JEL Kodları: I38 }\end{array}$ & $\begin{array}{l}\text { Düşünce kuruluşları, son yıllarda hem ulusal hem de uluslararası alanda kamu politikası süreçlerinin } \\
\text { önemli bir parçası olarak kabul edilmektedirler. Ancak düşünce kuruluşu kültürünün henüz yalnızca } \\
\text { gelişmiş ülkelerde yerleşmiş olduğu da bilinmektedir. Gelişmekte olan ülke statüsünde } \\
\text { değerlendirilen Türkiye'nin, gelişmişülkelerin uygulamalarını örnek alarak ve kendi iç dinamiklerine } \\
\text { uygun yeni stratejiler üreterek düşünce kuruluşlarını kamu politikası sisteminin içine dahil etmesi } \\
\text { gerekmektedir. Düşünce kuruluşlarının ülkedeki demokratik kalkınmaya değerli bir katk1 } \\
\text { sunabilecekleri düşünüldügünde bu çalışma Türkiye'de konu hakkındaki akademik literatüre katk1 } \\
\text { sunması amacıyla, düşünce kuruluşlarının etkili olmaları için önemli bir gösterge olan sosyal medya } \\
\text { kullanımı konusunu incelemektedir. Bu bağlamda, düşünce kuruluşlarının politika süreçlerinde etkili } \\
\text { olmak için güncel şartları sağlayıp sağlamadıkları hakkında resmi olarak kullandıkları sosyal medya } \\
\text { hesapları üzerinden bir inceleme yürütülmüştür. Çalışmanın temel sorusu düşünce kuruluşlarının } \\
\text { sosyal medya kullanımı ile hedef kitlelerine ulaşmayı, dolayısılyla da görünürlüklerini artırarak } \\
\text { politikalar üzerinde söz sahibi olmak için adım atmayı başarıp başaramadıklarıdır. Bu kapsamda, } \\
\text { çalışmada öncelikle düşünce kuruluşları kavramı ve literatürü üzerine kısa bir bilgi verildikten sonra } \\
\text { bu kuruluşların politika süreçlerinde aldıları ve almaya çalıştıları roller kısaca anlatılmaktadır. } \\
\text { Ardından almaya çalıştıkları rolleri almalarını sağlayacak bir etki kapasitesine erişmeleri için } \\
\text { izlemeleri gereken yol ve sosyal medya kullanımının bu yoldaki önemi tartışılmaktadır. Sonuç } \\
\text { olarak, düşünce kuruluşlarının sosyal medya mecralarında nasıl yer aldıkları verilerle analiz edilerek } \\
\text { bu konudaki etki kapasitelerini artırmaları için gerçekçi önerilerde bulunmak hedeflenmektedir. }\end{array}$ \\
\hline
\end{tabular}

\section{An Analysis on Social Media Usage of Think Tanks in Turkey}

\begin{tabular}{|c|c|}
\hline Article Info & ABSTRACT \\
\hline $\begin{array}{l}\text { Article History } \\
\text { Received: } 05.04 .2021 \\
\text { Accepted: } 14.05 .2021 \\
\text { Published: } 30.06 .2021 \\
\text { Keywords: } \\
\text { Think tanks, } \\
\text { Impact capacity, } \\
\text { Turkey, Social Media, } \\
\text { Public policy } \\
\text { JEL Codes: I38 }\end{array}$ & $\begin{array}{l}\text { Think tanks are recognized as important actors in both national and international public policy } \\
\text { processes in recent years. Nevertheless, it is known that the think tank culture has only settled in } \\
\text { developed countries. Turkey, as a developing country, needs to include think tanks in the public } \\
\text { policy system by producing new strategies in line with its internal dynamics. Considering that think } \\
\text { tanks can make a valuable contribution to democratic development in the country, this study } \\
\text { examines think tanks' social media activities, as a significant indicator for the impact capacity of } \\
\text { think tanks, to contribute to the academic literature on the subject in Turkey. In this context, we } \\
\text { researched their approved social media accounts to determine whether they meet the requirements to } \\
\text { be effective in policy processes. The main question of the study is whether think tanks have } \\
\text { succeeded in reaching their target audiences via social media or not. In this context, after a brief } \\
\text { explanation of the concept of think tanks and their literature, their roles and functions are explained. } \\
\text { Then, the way they need to follow to reach an impact capacity that can enable them to take the roles } \\
\text { they want. As a result, how they take part in social media channels is analyzed with the data, and } \\
\text { suggestions are made to increase their impact capacities. The ultimate goal of the study is to put } \\
\text { forward realistic suggestions for making think tanks effective actors both in the eyes of the public } \\
\text { and in decision-making processes. }\end{array}$ \\
\hline
\end{tabular}

Atıf/Citation: Kutlu, Ö. ve Karabulut, N. (2021). Türkiye'deki Düşünce Kuruluşlarının Sosyal Medya Kullanımları Üzerine Bir İnceleme, Necmettin Erbakan Üniversitesi Siyasal Bilgiler Fakültesi Dergisi, 3(1), 101-113.

"This article is licensed under a Creative Commons Attribution-NonCommercial 4.0 International License (CC BY-NC 4.0)"

\footnotetext{
* 1-3 Kasım 2019 tarihlerinde Bandırma On Yedi Eylül Üniversitesi tarafından düzenlenen 10. Sivil Toplum Kuruluşları Kongresi’nde sunulan ve tam bildiri olarak yayınlanan “Türkiye'deki Düşünce Kuruluşlarının Etki Kapasiteleri Bağlamında Önemli Bir Değişken Olarak Sosyal Medya Kullanımı” başlıklı konferans metninin güncellenmiş ve düzenlenmiş versiyonudur.
} 


\section{GİRISS}

Günümüzde kamu politikası yapıcılar bilgi eksikliğinden değil bilgi fazlalığından kaynaklanan bir bilgi kirliliğinden mustarip olmaktadırlar. İhtiyaç duyulan işlenmiş bilgi ve analize doğru zamanda ve doğru yerde ulaşmak da bu bağlamda hayati bir önem kazanmaktadır. Bu noktada, dünyada karar alıcıların güvenilir ve uygulamaya dökülebilir bilgiye ulaşmak için kullandıkları çeşitli kaynaklardan birisi olarak da düşünce kuruluşlarının yaygınlaştığı bilinmektedir (Bağc1 ve Aydın, 2009: 57). Karar alıcıların yanı sıra halkın da bilgiye ulaşması açısından düşünce kuruluşları son zamanlarda yükselen bir değer olmuşlardır. Tüm dünyada giderek yaygınlaşan ve ülkelerin politika oluşturmalarında önemli bir yer tutmaya başlayan düşünce kuruluşları üzerine Türkiye'de yapılan çalışmaların sayısının az olması da dikkat çekmektedir. Türkiye'de düşünce kuruluşları dünyadaki örnekleri kadar aktif olmamakla birlikte bu kuruluşlar üzerine yapılan akademik çalışmalar da diğer ülkelere nazaran düşük bir seviyede kalmaktadır. Her ne kadar 21. yüzyıldan itibaren düşünce kuruluşu sayısının artışına bağlı olarak ortaya çıkan çalışmalarda da bir artış görülse de düşünce kuruluşları üzerine Türkiye'de henüz geniş bir literatür bulunmamaktadır. Dolayısıyla Türkiye'de düşünce kuruluşu kültürünün geliştirilmesi üzerine öneriler sunan çalışmalara ihtiyaç duyulduğu ortadadır.

Son dönemlerde gelişmiş ülkelerde kamu politikası süreçlerinin değişmez bir parçası haline gelen düşünce kuruluşları, gelişmekte olan ülkelerde de niceliksel ve niteliksel olarak bir artış göstermektedir. Türkiye'nin de bu bağlamda gelişmiş ülkelerdeki örneklerden yola çıkarak kendi iç dinamiklerine uygun bir şekilde düşünce kuruluşlarını politika süreçlerine dahil etmesi beklenmektedir. Ayrıca düşünce kuruluşlarının teşvik edilmeleri, karar alıcılardan ve toplumdan hak ettikleri saygıyı görmeleri ve kamu politikası süreçlerine dahil edilmeleri; Türkiye'de sayılarının artması ve faaliyetlerini sürdürebilmeleri için bir ön koşul olarak ele alınabilir. Düşünce kuruluşlarının demokratik gelişmişlikle paralel bir şekilde etkili olabildikleri bilinirken öte yandan etkili oldukları durumda da demokratik gelişmişliğe katkıda bulundukları göze çarpmaktadır. Bu karşılıklı fayda ilişkisinden yararlanabilmek için etkili düşünce kuruluşu örneklerinin faaliyetleri örnek alınarak Türkiye'de de düşünce kuruluşu kültürünün yerleşmesi gerekliliği bu çalışmada vurgulanmaktadır.

Bu çalışmada düşünce kuruluşlarının temel amaçları olarak ifade edilen politika süreçlerine dahil olma ve bu süreçlerde aktif roller alarak alınan kararlarda etkili olma hedeflerinin, sosyal medya kanalları vasıtasıyla harekete geçirilmesi üzerine bir tartışma yürütülmektedir. Zira sosyal medya günümüzde kuruluşların görünürlüklerini ve etki kapasitelerini artırmalarında önemli bir araç olarak ön plana çıkmaktadır. Bu bağlamda çalışmada öncelikle düşünce kuruluşları hakkındaki literatüre değinildikten sonra sosyal medya ile olan ilişkileri irdelenmektedir. Sosyal medya yoluyla kamu politikaları üzerindeki etki kapasitelerini nasıl artırabilecekleri bu kuruluşların sosyal medya kullanımları üzerinden analiz edilmiştir. Düşünce kuruluşlarının sosyal medya kullanımlarının incelenmesi için Facebook ve Twitter kanalları seçilerek bu kanallar üzerinde gerçekleştirdikleri faaliyetler aktiflik düzeyleri ve paylaşım sıklıkları baz alınarak değerlendirilmiştir.

\section{DÜŞÜNCE KURULUŞLARI ÜZERİNE}

Düşünce kuruluşu ifadesi, İngilizce "Think Tank” kavramından gelmektedir. Think tank şeklinde konuşma dilinde Türkçe'ye geçmiş olsa da kavramın literatürde birçok farklı çevirisi bulunmaktadır. Ancak bunların içinde en çok kabul göreni düşünce kuruluşu ifadesidir. Öte yandan düşünce merkezi, fikir merkezi, araştırma merkezi, stratejik araştırma merkezi, düşünce tankı ve benzeri ifadelere de yer verilmektedir. İfadenin Türkçe'de tam karşılığı olmamasının yanında tanımlanmasında da sorun yaşandığı söylenebilir. Nitekim ifadenin sınırları çizilmiş veya genel kabul görmüş bir tanımı bulunmamaktadır (Bağcı ve Aydın, 2009: 59). Sorunun temelinde think tank ifadesinin dünya literatüründe çeşitli tanımlamalarının bulunması yatmaktadır. Düşünce kuruluşları; ekonomik 
kaynakları, insan kaynakları, çalışma alanları, bağımsız yahut bağımlı olmaları, kuruldukları ülkenin ve bölgenin siyasal kültürü, amaçları, hedefleri ve benzeri birçok nitelikleri bakımından belirli şekillerde birbirlerinden ayrışırlar. Mali ihtiyaçlarını nereden ve nasıl karşıladıkları, personellerinin nitelikleri ve çalışma yöntemleri, kuruldukları ülkenin kültürüne nasıl uyum sağladıkları ve bir önceki cümlede bahsedilen diğer nitelikler bağlamında düşünce kuruluşları üzerine yapılan tanımlar da çeşitlenmektedir. Aynı zamanda, bahsedilen nitelikler düşünce kuruluşlarının etki kapasitelerini, işlevselliklerini ve çalışma prensiplerini de yeniden düzenlemektedir.

Düşünce kuruluşları üzerine yapılmış olan farklı tanımlamalar incelendiğinde, ortak noktalar ve farklılaşan noktalar daha iyi analiz edilebilmektedir. Düşünce kuruluşları alanında uzmanlaşmış bazı akademisyenlerin tanımları bu konuyu açıklığa kavuşturmaktadır. Weaver ve McGann (2000: 5) düşünce kuruluşlarını; devlet, özel şirketler, çıkar grupları ve siyasi partiler gibi toplumsal çıkarlardan "önemli ölçüde özerk" siyasi araştırma örgütleri olarak tanımlamaktadırlar. Hames ve Feasy ise (1994: 216), düşünce kuruluşlarının genel tanımını, yine “'önemli ölçüde örgütsel özerkliğe sahip’, kâr amacı gütmeyen kamu politikaları araştırma enstitüleri” olarak yapmaktadırlar. James’e göre (1993: 492), düşünce kuruluşları, kamu politikalarını etkileme amacıyla disiplinler arası çalışmalar yürüten bağımsız kuruluşlardır. Rich'e göre ise (2001: 11), politika üretme sürecini etkilemek ve üretilen politikaları desteklemek amacıyla uzman oldukları alanlarda düşünceler üreten, bağımsız, çıkar gözetmeyen, kâr amacı gütmeyen siyasi örgütlerdir. Son olarak, Abelson (1996: 10) düşünce kuruluşlarını, "temel hedefleri kamu politikalarını ve kamuoyunu etkilemek olan, kâr amacı gütmeyen, tarafsız ama ideolojik davranabilen araştırma temelli enstitüler olarak tanımlamaktadır. Literatürde daha birçok farklı tanım bulunsa da daha önce de belirtildiği gibi, bu tanımlar bölgesel ve kültürel özelliklere göre bile değişiklik gösterebilmektedirler. Literatürdeki farklı tanımlardan yola çıkarak geniş bir düşünce kuruluşu tanımı yapmak gerekirse; düşünce kuruluşları kar amacı gütmeyen, araştırma yapma ve bu araştırmalar sonucunda ortaya belirli analizler çıkartma amacıyla kurulan, yaptıkları çalışmalar ile kamu politikası süreçlerinde etkili olmayı hedefleyen, aynı zamanda kamuoyunu bilgilendirmeyi ve bilinçlendirmeyi de amaçlayan, tarafsız ama ideolojik olabilen, bağımsız araştırma, strateji ve politika üretme merkezleridir (Karabulut, 2019: 8-9).

Düşünce kuruluşları, politikacıların karar vermeleri gereken konu üstüne bizzat araştırma yapmak için sınırlı zaman ve imkana sahip olmalarından ötürü bu kararlar için tavsiyelerde bulunarak politika süreçlerine dahil olurlar (Peetz, 2017: 256). Bilgi ve otorite arasında bir köprü kurmak bu anlamda en temel rolleri olarak ifade edilir (Weaver ve McGann, 2000: 3). Raporlar, araştırmalar, incelemeler, tavsiyeler, istihbarat kayıtları, özel dosyalar ve haberler gibi politika yapıcıların tek tek inceleyebileceği sınırı aşan aşırı miktarda bilgi kaynağının bulunması düşünce kuruluşlarının yaptıkları işin değerini artırmaktadır. Zira bilgi kirliliğinin çok ciddi bir sorun teşkil ettiği bir dönemde eldeki bilgileri derlemek, işlevsel hale getirmek ve karar vericilerin kullanabileceği bir forma getirmek düşünce kuruluşlarının en önemli rolü ve işlevidir. Ancak bu işlevi yerine getirebilmek için öncelikle politika süreçlerine dahil olabilecek kadar kendilerini ve çalışmalarını görünür kılmaları önemli bir ön koşuldur (Clark ve Roodman, 2013: 5). Düşünce kuruluşlarının politika süreçlerinde bir aktör olabilmek için göstermeleri gereken çaba da gün geçtikçe değişmektedir. Bilgi ve iletişim teknolojilerinde yaşanan gelişmelerin doğal bir sonucu olarak düşünce kuruluşlarının da kendilerini ve çalışmalarını tanıtmları için en uygun mecra internet ve dolayısıyla da sosyal medya olmuştur. Sosyal medya kanallarında sahip olunan takipçi sayısı, beğeni sayısı, aktivite düzeyi, paylaşım sıklığı ve benzeri göstergeler düşünce kuruluşlarının seslerini nasıl daha fazla duyurabileceklerinin görülebilmesi için başvurulacak başlıca veriler halini almıştır. Bu doğrultuda Türkiye'deki düşünce kuruluşlarının sosyal medya kullanımlarının analiz edilmesinin, etki kapasitelerinin artırılmasında kullanabilecek bulguları bize sağlayacağı düşünülmektedir. 


\section{Sosyal Medya ve Düşünce Kuruluşları}

Düşünce kuruluşlarının kamu politikası süreçlerine etkilerinin gözlenmesi için birçok yöntem denenmiştir. Ancak bu süreçlere etkilerinin doğrudan gözlemlenmesinin ulaşılması zor bir hedef olduğu deneyimlenmiştir. Nitekim, politika süreçleri sonucunda hazırlanan politika çıktısının düşünce kuruluşlarının etkisi ile şekillenip şekillenmediği üzerine yalnızca fikir yürütülebilir, açıkça bir kanıt yoksa kesin bir çıkarımda bulunulamaz. Bu sebeple bu çalışmada da olduğu gibi, literatürde genellikle düşünce kuruluşlarının süreçlerde etkili olmak için neler yaptıkları ve neler yapmaları gerektiği üzerinden bir değerlendirme yapılmaktadır. Kısaca ifade edilirse, düşünce kuruluşları yarattıkları etki üzerinden değil etki kapasiteleri üzerinden bir değerlendirmeye tabi tutulmaktadırlar. Nitekim, düşünce kuruluşlarının etki kapasitelerinin ölçülmesi üzerine birçok farklı çalışma bulunmaktadır. Bunlar arasında öne çıkan örnekler incelendiğinde birçoğunun sosyal medya kullanımını önemli bir değişken olarak ifade ettikleri görülmektedir. Örneğin, Allosio ve arkadaşları (2013) düşünce kuruluşlarının şeffaf, kamuya açık ve doğrulanabilir olup olmadıklarının resmî web siteleri ve sosyal medya hesapları üzerinden ölçülebileceğini savunurlar. Kuntz (2013), düşünce kuruluşarının etkisinin medyadaki görünürlük düzeyleri ve ürettikleri çıtıların kalitesi üzerinden gözlemlenebileceğini ileri sürer. Clark ve Roodman'a göre ise (2013), sosyal medya kullanımı, web sitesi trafiği, medya alıntıları ile bilimsel alıntılar ve örgüt kapasitesi düşünce kuruluşlarının etki kapasitelerinin en önemli belirleyicileridir. Özetle, medyada bir yer edinmek düşünce kuruluşlarının etkili olabilmeleri için önemli bir faktör olarak karşımıza çıkmaktadır.

Sosyal medya, düşünce kuruluşlarına faaliyetlerini toplum, politika yapıcılar, öğrenciler ve araştırmacılar dahil herkesin kullanımına kolayca sunma firsatını vermektedir. Bu nedenle, sosyal medya kullanımı, düşünce kuruluşlarının erişilebilirliğini, güvenilirliğini, popülerliğini ve dolayısıyla etki kapasitesini etkileyen önemli bir araç olarak ele alınabilmektedir (Clark ve Roodman, 2013). Basit bir şekilde düşünüldüğünde, düşünce kuruluşlarının sosyal medya üzerinden ne kadar insana ulaşabildikleri ne kadar aktif oldukları ve ne kadar talep edildikleri etki kapasitelerinin değerlendirilebilmesi için önemli birer gösterge halini almaktadırlar (Karabulut, 2019). Özellikle haber paylaşımının ve karşılıklı etkileşimin üst seviyede olduğu Twitter'da düşünce kuruluşlarının aktif olarak yer almaları bu anlamda önem kazanmaktadır (Tanner, 2012). Clark ve Roodman (2013: 19) ABD'deki düşünce kuruluşlarının sosyal medya başarılarını Twitter üzerindeki takipçi sayıları ve Facebook üzerindeki beğeni sayıları üzerinden değerlendirilmişlerdir. Diğer değişkenlerin de değerlendirilmesi sonucunda ulaşılan genel sıralamada sosyal medya başarısı en yüksek olan Brookings Institution ve Heritage Foundation'ın en üst sıralarda yer aldıkları sonucuna ulaşılmıştır. Ansfead ve Chadwick'in (2018: 257-260) 2015 Birleşik Krallık seçimleri sırasında düşünce kuruluşu IFS'nin Twitter faaliyetleri üzerine yaptıkları analizde de sosyal medya paylaşımlarının düşünce kuruluşunun otoritesini ve etkisini olumlu yönde etkilediği sonucuna ulaşılmıştır. Yine Castillo-Esparcia ve arkadaşlarının (2015: 233) Doğu Avrupa'daki düşünce kuruluşları üzerine yaptıkları çalışmada da düşünce kuruluşlarının sosyal medyada görünürlük, etkinlik ve etkileşim düzeylerinde varlığının etki kapasiteleri üzerinde etkili olduğu sonucuna varılmıştır. Bu kapsamda ele alındığında Türkiye'deki düşünce kuruluşlarının da Facebook ve Twitter üzerindeki mevcudiyetleri ve etkinlik düzeyleri incelenerek elde edilen veriler üzerinden değerlendirilmelerinin etkili olmaları açısından gösterge niteliğinde bir sonuç üreteceği öngörülmüştür.

\section{YÖNTEM}

Bu çalışmada, düşünce kuruluşlarının sosyal medya kullanımları ve sosyal medya aktiviteleri Facebook ve Twitter üzerinden bir değerlendirmeye tabi tutulmaktadır. Zira Facebook'taki beğeniler ve Twitter'daki takipçiler, modern dünyada popülerliğin bir göstergesi olarak kabul edilmektedir (Clark ve 
Roodman, 2013: 6). Ayrıca, bu ortamlardaki toplam paylaşım ve etkileşim sayılarının ile kullanım sıklıklarının düşünce kuruluşlarının sosyal medya aktivitelerinin birer göstergesi olarak değerlendirilmesi mümkündür. $\mathrm{Bu}$ nedenlerle bu çalışmada sosyal ağ analizi yöntemine başvurulmaktadır. Sosyal ağ analizi bir grubu birbirine bağlayan ilişkilerin incelenmesi yoluyla sosyal ağın değerlendirildiği yöntem olarak tanımlanmaktadır (Wasserman ve Faust, 1994). Çeşitli araştırma araçları kullanılması yoluyla bir sosyal ağın derinlemesine analizlerinin yapılmasına olanak sağlayan bu yöntem, bu çalışmada yalnızca düşünce kuruluşlarının sosyal medyada kendilerine nasıl bir ağ kurduklarını analiz etmek amacıyla herhangi bir araştırma aracına başvurmadan doğrudan manuel veri toplama yoluyla uygulanmıştır.

Çalışmanın evreni Türkiye'de faaliyet gösteren tüm düşünce kuruluşlarından oluşmaktadır. Ancak anlamlı bir sonuca ulaşılabilmesi amacıyla bu evrenden rastlantısal olmayan bir şekilde bir örneklem seçilmiştir. Örneklemin seçilmesinde düşünce kuruluşlarının derecelendirilmesinde dünya çapında kabul görmüş olan düşünce kuruluşu endeksi "Global Go to Think Tank Index (GGTTT )" (McGann, 2021) çalışmasına başvurulmuştur. Yıllık olarak dünyanın dört bir yanından 8000'den fazla düşünce kuruluşunun derecelendirildiği indeksin 2020 yılına ait raporu incelenmiş ve raporda farklı kategoriler altında derecelendirilmiş olan Türkiye'de faaliyet gösteren düşünce kuruluşları listelenmiştir. Son olarak çalışmanın amaç ve hedeflerine uygun olarak, listelenen kuruluşlar arasından hem Facebook hem de Twitter hesaplarına sahip olanlar seçilerek çalışmanın örneklemi olarak Tablo 1 'de gösterilmiştir.

Tablo 1'de görülebileceği üzere örneklemde toplamda 10 düşünce kuruluşu yer almaktadır. Çalışma, bu düşünce kuruluşlarının Facebook ve Twitter hesaplarından toplanan nicel veri ve bu veriler üzerine gerçekleştirilen analiz ve değerlendirme üzerine inşa edilmiştir. Çalışmanın amacı örneklemde yer alan kuruluşlarının sosyal medya aktivitelerinin Facebook ve Twitter kanalları vasıtasıyla ölçülerek etki kapasiteleri açısından değerlendirilmesi ve kuruluşların etkilerini artırabilmeleri için önerilerde bulunmaktır.

Tablo 1. Çalışmanın Örneklemini Oluşturan Düşünce Kuruluşları

\begin{tabular}{|c|c|c|c|c|}
\hline NO & ADI & MERKEZI & KURULUŞ YILI & WEBSİTESİ \\
\hline $\mathbf{1}$ & TESEV & İstanbul & 1994 & $\underline{\text { http://tesev.org.tr }}$ \\
\hline $\mathbf{2}$ & LDT & Ankara & 1994 & $\underline{\text { http://www.liberal.org.tr/ }}$ \\
\hline $\mathbf{3}$ & USTAD & Mardin & 2011 & $\underline{\text { http://www.ustad.org.tr }}$ \\
\hline $\mathbf{4}$ & TEPAV & Ankara & 2004 & $\underline{\text { https://www.tepav.org.tr }}$ \\
\hline $\mathbf{5}$ & TESAM & Bursa & 2008 & $\underline{\text { http://tesam.org.tr/ }}$ \\
\hline $\mathbf{6}$ & SETA & Ankara/İstanbul & 2005 & $\underline{\text { https://www.setav.org }}$ \\
\hline $\mathbf{7}$ & IPM & İstanbul & 2001 & $\underline{\text { http://ipc.sabanciuniv.edu }}$ \\
\hline $\mathbf{8}$ & ESI & Berlin & 1999 & $\underline{\text { https://www.esiweb.org }}$ \\
\hline $\mathbf{9}$ & ERG & İstanbul & 2003 & $\underline{\text { http://en.egitimreformugirisimi.org/ }}$ \\
\hline $\mathbf{1 0}$ & GPoT & İstanbul & 2009 & $\underline{\text { http://www.gpotcenter.org }}$ \\
\hline
\end{tabular}

Tablo 1'de verilen örneklemde yer alan kuruluşlar, Türkiye'de faaliyet gösteren düşünce kuruluşları arasında en ön planda yer almaktadırlar. Başlıca çalışma alanları demokratikleşme, iyi yönetişim, sosyal eşitlik olan TESEV (2021), GGTTT endeksinde "En iyi Düşünce Kuruluşları" listesinde 79. sırada, "En iyi medya kullanımına sahip düşünce kuruluşları" listesinde 41. sırada ve "Kamu politikasına en belirgin şekilde etki eden düşünce kuruluşları" listesinde 27. sırada yer almaktadır. Amaçlarını "Türkiye'nin problemlerine liberal ilkeler ışığında çözüm yolları bulmak ve kamu politikası üzerinde etkili olmak" olarak belirleyen LDT ise (2021), "En iyi Düşünce Kuruluşları" listesinde 90. ve "En iyi ekonomi politikası düşünce kuruluşları" listesinde 26. sıralarda yer almaktadır. 
Uluslararası İlişkiler üzerine uzmanlaşmış olan USTAD (2021) "En iyi Milli Güvenlik ve savunma düşünce kuruluşları" listesinde 78. sıradadır. Dış politika ve ekonomi üzerine yoğunlaşan ve 2015 y1lında Türkiye G20 dönem başkanlığını yürüten TEPAV (2021), "En iyi dış politika ve uluslararası ilişkiler düşünce kuruluşları" listesinde kendine 51. sırada yer bulmuştur. "Türkiye'yi yönetenlerin ufkunu açmak için gerekli teorik ve fikirsel zemini hazırlamak" amacıyla çalışmalar yürüten Bursa merkezli TESAM (2021), "En iyi Milli Güvenlik ve savunma düşünce kuruluşları” listesinde 91. ve "En iyi dış politika ve uluslararası ilişkiler düşünce kuruluşları" listesinde 114. sırada yer almaktadır. "Siyasal ve toplumsal "iyi”"nin inşasını" hedeflediğini ifade eden SETA (2021) "Bir siyasi partiye bağlı en iyi düşünce kuruluşları" listesinde 32. sıradadır. "Karar alıcılara ve kanaat önderlerine tarafsız analiz ve politika önerilerinde bulunmak" amacını taşıdığını belirten Sabancı Üniversitesi'ne bağlı bir kuruluş olan IPM (2021) "En iyi eğitim politikaları düşünce kuruluşları" listesinde 30. sırada bulunmaktadır. Berlin, Brüksel ve İstanbul olmak üzere üç ofiste faaliyet gösteren ESI, "demokratik kurumları ve insan hakları standartlarını liberal olmayan güçlere karşı savunabilecek bir Avrupa" amacı ile faaliyet göstermektedir (ESI, 2021) ve Türkiye'deki ofisinin faaliyetleri ile "Orta Doğu ve Kuzey Afrika'daki en iyi düşünce kuruluşları" listesinde 20. sırada yer bulmuştur. "Eğitimde karar süreçlerinin veriye dayalı olması, paydaşların katılımıyla gerçekleşmesi ve her çocuğun kaliteli eğitime erişiminin güvence altına alınması" amacıyla faaliyet gösteren ERG (2021), "En iyi eğitim politikaları düşünce kuruluşları" listesinde 46. sıradadır. Son olarak, Kültür Üniversitesi'ne bağlı olarak kurulan GPoT (2021); “yerel, ulusal ve uluslararası sorunlara şiddet içermeyen çözümler üretmek" amaciyla kurulmuştur ve "Üniversitelere bağlı en iyi düşünce kuruluşları" listesinde 70. sırada yer almaktadır (McGann, 2021). Özetle, örneklemde yer alan tüm kuruluşlar kamu politikalarına kendi uzmanlık alanları bağlamında etki etmek amacını taşıyan ve uluslararası anlamda kabul görmüş düşünce kuruluşları endeksinde yine kendi uzmanlık alanlarında kendilerine yer bulan kuruluşlardır. Bu kuruluşların sosyal medya hesaplarının incelenmesinin de bu kapsamda Türkiye'deki düşünce kuruluşlarının sosyal medya kullanımları için önerilerde bulunulmasında önemli bir gösterge niteliği taşıyacakları öngörülmüştür.

\section{BULGULAR}

Düşünce kuruluşlarının sosyal medyada sahip oldukları popülaritenin ölçülmesinin en etkili ve kolay yolunun takipçi sayılarına, etkileşim sayılarına ve kullanım sıklıklarına bakmak olduğu söylenebilir. Tablo 2'de örneklemde yer alan düşünce kuruluşlarının 3 Nisan 2021 tarihi itibariyle Facebook sayfalarının sahip olduğu beğeni sayısı ve Twitter hesaplarının sahip olduğu takipçi sayısı paylaşılmaktadır. We Are Social ve Hootsuite araştırma kuruluşları tarafindan hazırlanan "Digital in 2020" (2021) raporunda verilen bilgiye göre Türkiye'de 60 milyon sosyal medya kullanıcısı arasından \%79'unun Facebook ve \%73'ünün Twitter kullanıcısı olduğu bilindiğinde düşünce kuruluşlarının her iki mecrada da takip edilme sayılarının çok düşük seviyelerde kaldığı ifade edilmelidir. Ayrıca yine tabloda paylaşılan bilgilerden görülebileceği gibi örneklemde yer alan on düşünce kuruluşundan yalnızca iki tanesi doğrulanmış hesaplara sahiptir. Bu bağlamda Türkiye'deki düşünce kuruluşlarının tanınırlıklarını artırmada ve erişilebilir olmada sosyal medyayı kullanma konusunda başarılı olamadıkları çıkarımı yapılabilmektedir. Bunun arkasında hem kuruluşların kendisinden hem de hedef kitlenin ilgi düzeyinden kaynaklanan sorunlar bulunabilmektedir. Bu noktada düşünce kuruluşları açısından soruna yaklaşıldığında önemli olan nokta, sosyal medyanın bir etkileşim aracı olarak ne ölçüde aktif olarak kullanıldığıdır. 
Tablo 2. Örneklemdeki Düşünce Kuruluşlarının Sosyal Medya Takipçi Sayıları

\begin{tabular}{|l|c|c|}
\hline KURULUŞ & FACEBOOK BEĞENISI & TWITTER TAKİPÇísi \\
\hline TESEV $^{\mathbf{2}}$ & 3042 & 4039 \\
\hline LDT $^{\mathbf{3}}$ & 4017 & 4804 \\
\hline USTAD $^{\mathbf{4}}$ & 2876 & 468 \\
\hline TEPAV $^{\mathbf{5 6}}$ & 4319 & 27070 \\
\hline TESAM $^{\mathbf{7}}$ & 1887 & 930 \\
\hline SETA $^{\mathbf{9}}$ & 19185 & 92103 \\
\hline IPM $^{\mathbf{1 0}}$ & 3861 & 9236 \\
\hline ESI $^{\mathbf{1 1}}$ & 5925 & 6433 \\
\hline ERG $^{\mathbf{1 2}}$ & 12395 & 33712 \\
\hline GPOT $^{\mathbf{1 3}}$ & 1032 & 1429 \\
\hline Mean & 5853,9 & 18022,4 \\
\hline Medyan & 3939 & 5618,5 \\
\hline Minimum & 1032 & 468 \\
\hline Maksimum & 19185 & 92103 \\
\hline
\end{tabular}

Tablo 2 incelendiğinde Türkiye'de bulunan yaklaşık 47 milyon Facebook kullanıcısı ve 43 milyon Twitter kullanıcısı arasından düşünce kuruluşları ile en azından takip etmek yoluyla etkileşim içinde olan kullanıcıların oranının ortalama olarak \%1 seviyesine erişmeye bile çok uzak olduğu görülmektedir. Düşünce kuruluşlarının hedef kitleleri dikkate alındığında sosyal medyada çok daha geniş bir kitleye hitap etmelerinin gerektiği ortadadır. Zira en çok Facebook'ta ve Twitter'da en çok takip edilen kuruluş olarak görünen SETA'nın dahi Facebook'ta yalnızca 19185 sayfa beğenisi, Twitter'da ise 92103 takipçisi bulunduğu görülmektedir. Ortalama (mean) değer üzerinden bir değerlendirme yapıldığında tabloda mevcut olan sayıların hedef kitleye erişimin etkin olarak sağlanabilmesi için en azından on kat artırılması gerektiği düşünülmektedir. Medyan değerleri incelendiğinde ise daha da kötü bir sonuçla karşılaşılmaktadır. Medyan değerinin ortalama değerden büyük oranda düşük bir seviyede olması ortalama değerin yalnızca bir veya birkaç kuruluş tarafindan yükseltildiğini göstermektedir. Kısacası, tablodan çıkarılan sonuca göre, Türkiye'de faaliyet gösteren düşünce kuruluşlarının hedef kitlelerine sosyal medya aracılı̆̆ 1 ile ulaşamadıkları rahatlıkla ifade edilebilmektedir. Özellikle Türkiye gibi gündemin ve siyasi olayların Twitter üzerinde çokça dillendirildiği ve takip edildiği bir konjonktürde Twitter'da popülaritelerini artıramamaları büyük bir eksiklik olarak algılanmalıdır.

Sosyal medya popülaritesi açısından durumun hiç parlak olmadığı göz önünde bulundurulduğunda sosyal medyada gerçekleştirilen etkileşimlerin değerlendirilmesinin çalışmaya

\footnotetext{
${ }^{2}$ TESEV'e Facebook'ta ve Twitter'da @tesev2015 kullanıcı adreslerinden erişilmiştir. (Erişim tarihi: 03.04.2021)

3 LDT’ye Twitter'da@liberal_dusunce ve Facebook'ta@) @liberaldusunce kullanıcı adreslerinden erişilmiştir. (Erişim tarihi: 03.04.2021)

${ }^{4}$ USTAD'a Twitter'da @ustadstrateji ve Facebook’ta @USTADstrateji kullanıcı adreslerinden erişilmiştir. (Erişim tarihi: 03.04.2021)

${ }^{5}$ TEPAV'a Facebook ve Twitter'da @tepav kullanıcı adresinden erișilmiștir. (Erișim tarihi: 03.04.2021)

${ }^{6}$ TEPAV'ın Facebook ve Twitter hesapları “doğrulanmış" hesap statüsündedir.

7 TESAM'a Facebook ve Twitter'da @tesamtr kullanıcı adresinden erișilmiștir. (Erișim tarihi: 03.04.2021)

${ }^{8}$ SETA'ya Twitter'da@setavakfi ve Facebook’ta@setav kullanıcı adreslerinden erişilmiştir. (Erişim tarihi: 03.04.2021)

${ }^{9}$ SETA'nın Facebook ve Twitter hesapları "doğrulanmış" hesap statüsündedir.

${ }^{10}$ IPM'ye Facebook'ta @IstanbulPolicyCenter ve Twitter'da @ipc_ipm kullanıcı adreslerinden erişilmiştir. (Erişim tarihi: 03.04.2021)

${ }^{11}$ ESI'ye Facebook'ta@europeanstabilityinitiative ve Twitter'da @ESI eu kullanıcı adreslerinden erişilmiştir. (Erișim tarihi: 03.04.2021)

${ }^{12}$ ERG'ye Twitter'da @egitimreformu ve Facebook’ta @egitimreformugirisimi kullanıcı adreslerinden erișilmiştir. (Erişim tarihi: 03.04.2021)

${ }^{13}$ GpoT’a Facebook ve Twitter’da @gpotcenter kullanıcı adresinden erișilmiștir. (Erișim tarihi: 03.04.2021)
} 
katkısı olmayacağı çıkarımı yapılabilmektedir. Zira örneklemde yer alan düşünce kuruluşları, hedef kitlelerinin çok küçük bir kısmı ile sosyal medyada ilişki içerisinde olma firsatı bulduklarından dolayı dahil oldukları etkileşimin değerlendirilmesi sonucunda ortaya çıkan bulgular kuruluşların hedef kitleleri ile sosyal medyada kurdukları etkileşim durumunu açığa çıkarmak açısından doğru sonuçlar vermeyecektir. $\mathrm{Bu}$ durumda, düşünce kuruluşlarının sosyal medya kanallarını kullanım sıklıklarının incelenmesinin sorunun temellerine yönelik bir çıkarım yapılabilmesi için faydalı olacağ düşünülmüştür. Bu bağlamda Tablo 3'te düşünce kuruluşlarının sosyal medya paylaşımlarının sıklığı verilmektedir. Paylaşım sıklıklarının incelenmesi için; Facebook'ta saat başına kaç paylaşım yapıldığı üzerine elde edilen veri, 27.10.2019 tarihinde Facebook veri tabanlı olarak hizmet veren sosyal ağ analizi uygulaması "Netvizz" (Rieder, 2013) yardımı ile elde edilen verinin üzerine, uygulamanın hizmete kapanmış olması nedeniyle 03.04.2021 tarihine manuel olarak hesaplanarak tamamlanması yoluyla elde edilmiştir. Twitter'da ne sıklıkla paylaşım yapıldığı üzerine elde edilen veri ise kuruluşların Twitter hesaplarının paylaştıkları tweet sayılarının ve Twitter'a kaydolma tarihlerinin manuel olarak incelenmesi yoluyla listelenmiştir. Tablo 3'te paylaşılan istatistikler, 3 Nisan 2021 tarihinde anlık olarak gerçekleşmiş olan verileri yansıtmaktadır.

Tablo 2. Örneklemdeki Düşünce Kuruluşlarının Sosyal Medya Takipçi Sayıları

\begin{tabular}{|c|c|c|}
\hline KURULUŞ & $\begin{array}{c}\text { FACEBOOK PAYLAŞIMI } \\
\text { (SAAT BAŞINA) }\end{array}$ & $\begin{array}{c}\text { TWEET SAYISI } \\
\text { (SAAT BAŞINA) }^{\text {14 }}\end{array}$ \\
\hline TESEV & 0.04 & 0.038 \\
\hline LDT & 0.04 & 0.032 \\
\hline USTAD & 0,01 & 0.023 \\
\hline TEPAV & 0.14 & 0.11 \\
\hline TESAM & 0.11 & 0.022 \\
\hline SETA & 0.26 & 0.42 \\
\hline IPM & 0,25 & 0.044 \\
\hline ESI & 0.18 & 0.036 \\
\hline ERG & 0.22 & 0.062 \\
\hline GPOT & 0 & 0.013 \\
\hline Mean & 0.115 & 0,08 \\
\hline Medyan & 0.125 & 0.037 \\
\hline Minimum & 0 & 0.013 \\
\hline Maksimum & 0.26 & 0.42 \\
\hline
\end{tabular}

Sosyal medya kullanım sıklığı ve sosyal medyadaki etkinlik yine birçok farklı yöntemle ölçülebilmektedir. Ancak kuruluşların belirli bir zamandaki paylaşım sıklıklarının ölçülmesi bunun en doğrudan ölçüm şekli olarak karşımıza çıkmaktadır. Tekrar "Digital in 2020" raporuna baktığımızda, Türkiye'de Facebook sayfaları tarafından saat başına ortalama 1,16 adet paylaşımda bulunulurken Twitter'da saat başına ortalama 1,8 adet tweet atıldığı görülmektedir (We are Social ve Hootsuite, 2021). $\mathrm{Bu}$ veriler 1şığında Tablo 3’te verilen paylaşım sıklıkları analiz edildiğinde; düşünce kuruluşlarının Türkiye ortalamasına kıyasla hem Facebook'ta hem de Twitter'da yaklaşık olarak 1/20 oranında daha az paylaşımda bulundukları ortaya çıkmaktadır. Ayrıca, bu kıyaslama ortalama değer üzerinden değil de medyan değer üzerinden yapılırsa paylaşım sıklıkları arasındaki oranın 1/50'lere kadar vardığı ifade edilmelidir. Hedef kitlelere ulaşmak için paylaşım, duyuru ve bilgilendirme yapılabilmesinin yanı sıra karşılıklı etkileşimde bulunma imkânı da sağlamakta olan sosyal medya mecralarında paylaşım sıklığının en azından gündemde kalabilmek için önemli olduğu bilindiğine göre, düşünce kuruluşlarının

${ }^{14}$ Düşünce kuruluşlarının toplam tweet sayılarının Twitter’a katıldıkları zamandan 3 Nisan 2021 tarihinde verilerin toplandığı zamana kadar arada geçen toplam saate bölünmesi sonusunda elde edilmiştir. 
sosyal medyada yeterince paylaşımda bulunmadıkları yahut yeterli paylaşımda bulunmalarına olanak sağlayacak düzeyde faaliyet kapasitesine ulaşamadıkları çıkarımı kolaylıkla yapılabilmektedir.

\section{SONUÇ VE ÖNERILER}

Toplumsal ve siyasi alanda etkili olmak isteyen örgütlerin teknolojiyi, BİT'leri ve özellikle de sosyal medyayı etkili kullanmaları günümüzde bir zorunluluk halini almıştır. Teknolojinin toplumların gelişiminde başat role sahip olduğu toplum 5.0 felsefesi kapsamında değerlendirdiğimizde, sosyal medya kullanımı etkili ve başarılı olabilmek için kaçınılmaz olduğunu ifade etmek mümkündür. $\mathrm{Bu}$ nedenle düşünce kuruluşları için de sosyal medya kullanımının taşıdığ Türkiye'deki düşünce kuruluşlarının sosyal medyada sahip oldukları popülarite ve sosyal medya kullanım etkinlikleri değerlendirilerek günümüz şartlarına uygun bir şekilde üstlerine düşen görevi yerine getirip getirmedikleri ortaya konulmaya çalışılmıştır. Ancak çalışmanın bulguları açıkça göstermiştir ki Türkiye'de faaliyet gösteren düşünce kuruluşları sosyal medya mecralarında, toplumsal ve siyasal alanlardaki etkilerini artırabilecekleri bir etkinlik düzeyine sahip değildir. Zira hem sosyal medyada kazanmış oldukları popülarite hem de sosyal medya kanallarını kullanım sıklıkları açısından olması gerekenin çok altında bir performansa sahip oldukları kolaylıkla tespit edilebilmektedir. $\mathrm{Bu}$ çalışmanın sonucu olarak Türkiye'de düşünce kuruluşlarının sosyal medya kullanımı açısından başarısız oldukları rahatlıkla söylenebilir.

Hedef kitlelerine hızlı ve etkili bir yoldan ulaşabilmek, bu vesileyle etki alanlarını genişletmek ve amaçlarına ulaşabilmek için düşünce kuruluşlarının sosyal medyadaki aktivitelerini gözden geçirmeleri ve bu konuda somut adımlar atmaları gerektiği bu çalışmanın temel önerisi olarak ön plana çıkmıştır. $\mathrm{Bu}$ temel öneriden yola çıkarak düşünce kuruluşlarının sosyal medya kullanımları üzerine şu öneriler siralanabilir:

- İlk olarak, sosyal medya hesaplarına kurumsal bir kimlik kazandırmaları ve hedef kitlelerine resmi bir sosyal medya hesabına sahip olduklarını göstermeleri gerekir. Zira doğrulanmış hesaplar, diğer kullanıcılar tarafından daha güvenilir ve ilgi çekici olarak algılanmaktadır (Hentschel vd., 2014:2-3).

- İkinci olarak, sosyal medyada yaptıkları paylaşım sayısı içeriği ve niteliği de güçlendirilerek artırılmalıdır. Düzenledikleri faaliyetler, yayınladıkları çalışmalar ve kuruluşun ilanları ve duyuruları sosyal medya aracılı̆̆ıyla daha fazla kişiye ulaştırılmaya çalışılmalıdır. Ayrıca sosyal medya kanallarında yapılan paylaşımlara cevap olarak yahut doğrudan kuruluşun hesabından bahsederek etkileşim kurmaya çalışan kullanıcılara yine nitelik göz önünde bulundurularak imkân dahilinde geri dönüş yapılmalıdır.

- $\quad$ Üçüncü olarak, kuruluşların sosyal medyada birbirleri ile ve diğer kamu politikası aktörleri ile etkileşim içinde olarak sosyal medyayı bir çeşit ağ oluşturma alanı olarak değerlendirmeleri gerekmektedir.

- Dördüncü olarak, kullanıcı dostu içerikler üreterek hedef kitlelerinin ilgisini çekmeli ve kullanıcıya fırsatlar sunan paylaşımlara ağırlık vermelidirler. Sosyal medya paylaşımlarının içeriği net, anlaşılır ve açıklayıcı olmalıdır.

- $\quad$ Son olarak, özellikle faaliyet yürüttükleri alan özelinde sosyal medyada etkin olarak rol almaları gerekmektedir. Sahada gereken rolleri alıyor olsalar dahi sosyal medya artık birçok alanda bilgilendirme, bilinçlendirme, kampanya, reklam ve dayanışma çalışmalarının merkezi konumuna gelmiştir. $\mathrm{Bu}$ anlamda sosyal medyada yer alan projelerin ve çalışmaların düşünce kuruluşlarına etkilerini artırmada önemli bir katkısı olacağı düşünülmektedir (Kutlu ve Karabulut, 2019). 


\section{KAYNAKÇA}

Abelson, D. E. (1996). American Think-Tanks and their Role in US Foreign Policy, $1^{\text {st }}$ Ed., MacMillan Press: Londra

Alloisio, I., Bertolin S., Farnia L., Giove S., ve Trevisan J. (2013). The 2012 ICCG Climate Think Tank Ranking: A Methodological Report. Venedik, Italya: International Center for Climate Governance.

Anstead, N., \& Chadwick, A. (2017). A primary definer online: the construction and propagation of a think tank's authority on social media. Media, Culture \& Society, 40(2): 246-266.

Bağc1, H. ve Aydın A. (2009). "Dünyada ve Türkiye'de Düşünce Kuruluşu Kültürü”, Türkiye'de Stratejik Düşünce Kültürü ve Stratejik Araştırma Merkezleri: Başlangıcından Bugüne Türk Düşünce Kuruluşları, Ed. Hasan Kanbolat ve H. Ali Karasar, 1. Basım, Nobel Yayınları: Ankara, 57-124.

Castillo-Esparcia, A., Almansa-Martínez, A., ve Smolak-Lozano, E. (2015). East European think tanks in social media - towards the model of evaluation of effective communication/PR strategies: Case study analysis. Catalan Journal of Communication \& Cultural Studies, 7(2): 231-250.

Clark, J. ve Roodman D. (2013). "Measuring Think Tank Performance: An Index of Public Profile." CGD Policy Paper 025. Washington DC: Center for Global Development. Erişim Adresi http://www.cgdev.org/publication/metrics-think-tank-profile Erişim Tarihi 03.04.2021

ERG (2021). Yeni Bir Fikir Üretim Merkezi: Ĕ̈itim Reformu Girişimi, Erişim Adresi https://www.egitimreformugirisimi.org/hakkimizda/ Erişim Tarihi 04.04.2021

ESI (2021). Who we are, Erişim Adresi https://www.esiweb.org/who-we-are Erişim Tarihi 04.04.2021

GPoT (2021). Who we are, Erişim Adresi http://www.gpotcenter.org/about Erişim Tarihi 03.04.2021

Hames, T. ve Feasy R. (1994). "Anglo-American Think Tanks under Reagan and Thatcher", A Conservative Revolution? The Thatcher-Reagan Decade in Perspective, Ed. A. Adonis ve T. Hames, Manchester University Press: Manchester, 215-237.

Hentschel, M., Alonso, O., Counts, S., \& Kandylas, V. (2014). "Finding users we trust: Scaling up verified Twitter users using their communication patterns". Eighth International AAAI Conference on Weblogs and Social Media, Haziran 1-4, Ann Harbor: Michigan.

IPM (2021). İstanbul Politikalar Merkezi. Erişim Adresi https://ipc.sabanciuniv.edu/tr/hakkimizda Erişim Tarihi 03.04.2021

James, S. (2000). "Influencing Government Policy Making", Banking on Knowledge: The Genesis of the Global Development Network, Diane Stone (ed.). Routledge: London, 165-182

Karabulut, N. (2019). Impact Capacity of Think Tanks in Turkey (Yayımlanmamış Yüksek Lisans Tezi). Necmettin Erbakan Üniversitesi Sosyal Bilimler Enstitüsü: Konya

Kuntz, F. (2013). Communications and Impact Metrics for Think Tanks. The Centre for International Governance Innovation. Erişim Adresi https://www.cigionline.org/articles/communications-and-impact-metrics-thinktanks Erişim Tarihi 28.03.2021

Kutlu, Ö ve Karabulut N. (2019). "Türkiye'deki Düşünce Kuruluşlarının Etki Kapasitesi Bağlamında Önemli Bir Değişken olarak Sosyal Medya Kullanımı”. 10. Uluslararası Sivil Toplum Kuruluşları Kongresi, 1-3 Kasım 2019, Balıkesir: Türkiye, 354-364

LDT (2021). LDT Hakkında. Erişim Adresi http://www.liberal.org.tr/sayfa/ltd-tarihce,1.php Erişim Tarihi 04.04.2021

McGann, J. (2021). "2020 Global Go To Think Tanks Index Report”, TTCSP. Erişim Adresi https://repository.upenn.edu/cgi/viewcontent.cgi?article=1019\&context=think_tanks Erişim Tarihi 03.04.2021

Peetz, D. (2017). "Why Establish Non-Representative Organizations? Rethinking the Role, Form and Target of Think Tanks". Ed. A. Salas-Porras ve G. Murray, Think Tanks and Global Politics, Palgrave Macmillan: New York, 245-264.

Rich, A. (2001). Think Tanks and the Intersection of Ideology, Advocacy, and Influence, NIRA Review, 1: 51-68. 
Rieder, B. (2013). Studying Facebook via Data Extraction: The Netvizz Application. WebSci'13, May 2-4, Paris, France

SETA (2021). Hakkımızda. Erişim Adresi https://www.setav.org/hakkimizda/ Erişim Tarihi 03.04.2021

Stone, D. ve Garnett M. (1998). “Think Tanks, Policy Advice and Governance”, Think Tanks Across Nations: A Comparative Approach, Ed. D. Stone, A. Denham ve M. Garnett, Manchester University Press: Manchester, 1-20.

Tanner, J. (2012). "Social Media and think tanks: lessons from London Thinks,” On Think Tanks. Erişim Adresi https://onthinktanks.org/articles/social-media-and-think-tanks-lessons-from-london-thinks/ Erişim Tarihi 12.05.2021

TEPAV (2021). Tepav nedir?. Erişim Adresi https://www.tepav.org.tr/tr/html/250/Hakkimizda/ Erişim Tarihi 03.04.2021

TESAM (2021). Hakkımızda. Erişim Adresi https://tesam.org.tr/hakkimizda/ Erişim Tarihi 03.04.2021

TESEV (2021). Hakkımızda. Erişim Adresi https://www.tesev.org.tr/tr/turkiye-ekonomik-ve-sosyal-etudler-vakfi/ Erişim Tarihi 03.04.2021

USTAD (2021). USTAD Hakkında. Erişim Adresi http://www.ustad.org.tr/?page_id=2 Erişim Tarihi 03.04.2021

Wasserman, S. ve Faust K. (1994). Social Networks Analysis: Methods and Applications. Cambridge University Press: Cambridge

We Are Social ve Hootsuite (2021). Digital in 2020 Report. Erişim Adresi https://wearesocial.com/global-digitalreport-2019 Erişim Tarihi 28.03.2021

Weaver, R. K. ve McGann J. (2000). "Think Tanks and Civil Societies in a Time of Change", Think Tanks and Civil Societies: Catalysts for Ideas and Action, Ed. J. McGann and R. K. Weaver. Transaction Publishers: New Jersey, 1-36. 


\section{EXTENDED ABSTRACT}

A discussion is conducted in this study on the realization of the goals of think tanks to be involved in policy processes and to be effective in decisions taken by taking active roles in these processes through social media. Today, social media stands out as an outstanding tool for organizations to increase their visibility and impact capacity. In this context, firstly, the literature on think tanks is mentioned, and then their relations with social media are examined. How these organizations can increase their impact capacities on public policies through social media has been analyzed through their social media activities. Facebook and Twitter were selected to examine think tanks' social media usage, and their activities on these channels were evaluated based on their activity levels and frequency of posting.

Think tanks are involved in policy processes by making recommendations for the decisions since policymakers have limited time and opportunity to research the issue, which they should decide on (Peetz, 2017: 256). Building a bridge between knowledge and authority is expressed as their most fundamental role in this sense (Weaver \& McGann, 2000: 3). The excessive amount of information available to policymakers, such as reports, surveys, reviews, recommendations, intelligence records, and news, adds to the value of think tanks. In a period when information pollution poses a serious problem, it is the most significant role and function of think tanks to compile the available information, to make them functional, and to bring them into a form that can be used by decision-makers. However, to fulfill this function, it is a precondition for them to make themselves and their work visible enough to be included in the policy processes (Clark \& Roodman, 2013: 5). The effort that think tanks should show to become an actor in policy processes has also changed day by day. As a natural consequence of the developments in information and communication technologies, the most suitable medium for think tanks to introduce themselves and their work is the internet- and therefore, social media. The number of followers, number of likes, activity level, posting frequency, and similar indicators on social media channels have become the data to be consulted to see how think tanks can make their voices louder. In this regard, analyzing the use of social media by think tanks in Turkey will provide us the findings that can be utilized to increase their impact capacities.

There are many studies on measuring the impact capacities of think tanks. When the prominent examples among these are examined, it is seen that most of them express the use of social media as a significant variable. For instance, Allosio et al. (2013) argue that whether think tanks are transparent, public, and verifiable can be measured through official websites and social media accounts. Kuntz (2013) suggests that the impacts of think tanks can be observed through their level of visibility in media channels and the quality of their outputs. According to Clark and Roodman (2013), social media usage, website traffic, media citations, scientific citations, and organizational capacity are the most outstanding determinants of the impact capacities of think tanks. In summary, gaining a place in the media emerges as a factor for think tanks to be effective.

Social media allows think tanks to easily make their activities available to everyone, including the community, policymakers, students, and researchers. For this reason, the use of social media can be considered as an important tool that affects the accessibility, reliability, popularity, and thus the impact capacity of think tanks (Clark \& Roodman, 2013). Therefore, how many people think tanks can reach through social media become an indicator of how active they are (Karabulut, 2019).

According to the findings of the study, it is seen that among approximately 47 million Facebook users and 43 million Twitter users in Turkey, the rate of users following think tanks is far from reaching the level of $1 \%$. Considering the target audiences of think tanks, it is obvious that they should appeal to a much wider audience on social media. In addition, it is seen that think tanks share approximately 1/20 less on both Facebook and Twitter compared to the country average.

The main recommendation of this study is that think tanks should review their social media policies and take concrete steps to reach their target audiences in a fast and effective way. Thus, they can expand their sphere of influence and achieve their goals. Based on this basic recommendation, the following suggestions can be listed on think tanks' social media activities:

- $\quad$ First, they need to give their social media accounts a corporate identity and show their target audience that they have an official social media account. Because verified accounts are perceived as more reliable and attractive by other users (Hentschel et al., 2014: 2-3).

- Secondly, they should increase the number of posts they share on social media by strengthening their content and quality. They should reach more people through social media by sharing their activities, studies, and announcements. Besides, users who try to interact in response to the posts made on social media channels or directly mentioning the account of the organization should be replied to, if possible. 
- Thirdly, they need to consider social media as a platform for networking of interacting with each other and other public policy actors.

- $\quad$ Fourthly, they should attract the attention of their target audience by producing user-friendly content, and they should focus on sharing that offers opportunities to the users. The content of social media posts should be clear, understandable, and descriptive.

- $\quad$ Finally, they need to take an active role in social media, especially in their field of activity. Even if they take on the required roles in the field, social media has now become the center of information, awarenessraising, campaign, advertising, and solidarity activities in many areas. In this sense, it is obvious that projects and studies on social media can make a significant contribution to increasing the effects of think tanks. 